\title{
Diş hekimliği eğitiminde beceri kavramı: 21. Yüzyıl becerileri
}

\author{
Funda Akaltan(0000-0001-6744-6312) ${ }^{\alpha}$
}

Selcuk Dent J, Diş Hekimliği Eğitimini Yeniden Düşünmek - Özel Sayı

(Doi: 10.15311/selcukdentj.568429)

Bașvuru Tarihi: 21 Mayıs 2019 Yayına Kabul Tarihi: 01 Ağustos 2019

öz

Diş hekimliği eğitiminde beceri kavramı: 21. Yüzyıl becerileri

Diş hekimliğinde beceri kavramı; akla mesleki becerileri getirir Oysa ki; mezun diş hekimlerinin sadece klinik beceri kazanmakla kalmayıp, topluma iyi hizmet sunabilmek için - iletişim, düşünme ve problem çözme, takım çalışması gücü, hayat boyu öğrenme ve bilgi yönetimi, girişimcilik, etik, ahlak ve profesyonellik ve liderlik gibi - 21. yüzyıl becerilerine sahip olmaları da gerekir. Hekimlerin etkili uyum becerisine sahip olması durumunda, hasta memnuniyetinin ve tedaviden sağlanan faydanın arttığı hasta anksiyetesinin ve hasta şikayetlerinin azaldığ bilinmektedir. Diş hekimlerinin tedavi uygulamalarında güncel bilgi ve becerileri yakalamaları, zor tedavi planlamalarını baş edebilmeleri, çalışma ortamlarındaki işbirlikçi çalışmaya uyum sağlamaları açısından da uyum becerilerinin önemi büyüktür. Yetkin mezunların yetiştirilmesi için fakültelerin müfredatlarında uyum becerisi eğitimine de yer vermeleri beklenir.

\section{ANAHTAR KELIMELER}

Diş hekimliği eğitimi, beceri eğitimi, 21. yüzyıl becerileri

\begin{abstract}
Skill concept in dental education: 21st Century skills

Professional skills are basically considered in dental education when the skill concept is mentioned as a training activity. However, students in a professional undergraduate program such as dentistry are expected to not only be clinically competent upon graduation but also to exhibit good 21 st century skills such as communication, critical thinking and problem-solving, teamwork, leadership, professional ethics and morals, lifelong learning and entrepreneurship in order to serve the society at large. Dentists to have good soft skills can easily increase the patient satisfaction and the benefits from dental treatment while decreasing the patient anxiety and patient complaints. Soft skills have a great affect on dentists' to be able to follow update dental technology and treatments, to manage cases requiring challenging treatment planning and to cooperate with interprofessional behaviors. Therefore soft skill training has to take place in the curriculum development of dental faculties to be able to have competent graduates.
\end{abstract}

\section{KEYWORDS}

Dental education, skill training, soft skills, 21st century skills

Günümüz diş hekimliği pratiği; beklentileri gittikçe artan ve hakkını savunan hastalarla baş edebilme, gelişen bilgi ve tedavi seçenekleri hakkında farkındalık ve multidisipliner işbirliğini gerektirir. ${ }^{1}$

Eğitim kurumlarının yüksek düzeyde tedavi hizmeti sunabilen ve günlük tedavilerdeki sorunlarla baş edebilen yeterli ve donanımlı diş hekimleri yetiştirmeleri beklenir. ${ }^{2}$ Öğrencilerin diş hekimi olmaya geçişinde, eğitim kurumları, teorik eğitimden preklinik ve klinik eğitime varan birçok öğretme stratejisini bir arada kullanırlar. ${ }^{3}$ Bu süreç içinde üretilen eğitimin etkinliğini değerlendirmek için ölçme yöntemleri önemli yer tutar ve öğrencilerin öğrenim çıktılarına ulaşıp ulaşmadıkları belirlenir. Etkili bir eğitim vermenin yolu; hem öğretme hem de değerlendirme stratejilerinin klinik gerçeklerden çıkan gereksinimlere dayanan öğrenim çıktılarıyla buluşmasıdır. ${ }^{4}$

Müfredat geliştirme çalışmalarında esas alınan ve mezunlar için tüm dünyada geçerli olan bazı yeterlik profilleri öne sürülmüştür. ${ }^{2,5,6}$ Bölgeler arasındaki toplumsal farklara rağmen, bu yeterlik profilleri "çekirdek yeterlikler" olarak genel bir zemini paylaşarak, güvenli ve bağımsız diş hekimliği pratiğinin kazanılmasına imkan sağlar. ${ }^{7}$ Çekirdek

\footnotetext{
${ }^{\alpha}$ Ankara Üniversitesi Diş Hekimliği Fakültesi, Protetik Diş Tedavisi Anabilim Dalı, Ankara
} 
yeterlikler; profesyonellik, iletişim ve toplum becerileri, değerlendirme ve tedavi planlamasını kapsayan hasta tedavisi, sağlığın korunması ve iyileştirilmesi ile bilimsel ve klinik bilginin idaresini kapsar. Yeterlik profillerinin diş hekimliği eğitiminin öğrenim çıktılarını geliştirmede ayrıntılı plan olarak kullanımı önerilir; toplumsal değişimler göz önünde tutularak yeterliklerin de güncellenmesi gerekir. ${ }^{5}$

Fakültelerin lisans diş hekimliği eğitimini klinikteki gerçeklerle ilişkilendirme sorumluluğu da vardır. Yeterliklerin klinik gerçeklerle uyumluğu Flaman diş hekimlerine sorularak değerlendirilmiş; ${ }^{1}$ yeterliklerin gerekliliği konusunda ortak görüş sağlanmıştır. Bunun yanı sıra, muayenehane yönetimi, muhasebe ve vergilendirme veya stres yönetimi gibi konuların inmal edildiği bildirilmiştir. İleri düzeyde tedavi hizmeti üretmek için müfredatların gelişen klinik gerçeklerle uyumlu olarak düzenlenmesini içeren bir strateji geliştirilmesi gerektiği vurgulanmıştır. ${ }^{1}$

Lisans diş hekimliği eğitiminin yapısı; tanımlanmasına da karmaşıklık ve zorluk getirir. ${ }^{8}$ Diş hekimliğinde uygulama yapmak; ileri seviyede karar verme ve teknik beceriyi gerektirir. ${ }^{9}$ Dental uygulamaların yapısı sadece öğrenim ve öğretim, eğitmen-öğrenci ilişkileri değil, hasta huzuru ve beklentileri, klinik sonuçlar ve komplike materyal ve yöntemleri de içerir. ${ }^{10}$ Mesleğin uzmanları; diş hekimliğinin esasen geri dönüşümü olmayan işlemler ve hastalardaki emosyonel davranışların idaresini içerdiği görüşünde birleşmişlerdir. Diş hekimliği öğrencileri; diğer sağlık meslek gruplarının aksine invaziv ve geri dönüşü olmayan işlemlerle yüzleşirler.

Lisans diş hekimliği klinik eğitimi; mezunların bağımsız klinik pratiğini sergileyebilecekleri şekilde istenen öğrenim çıktıları ve tüm alanlardaki yeterlikleri içeren bir müfredat gerektirir. ${ }^{11}$

Bu derleme çalışmasında; mezuniyet yeterliklerini karşılamada en önemli yeri tutan "beceri kavramı" ve diş hekimliği için becerinin alt bileşenleri olan "mesleki (klinik) beceriler" yanında, 21. yüzyıl becerileri olarak da ifade edilen "uyum becerileri (soft skills)" ve eğitim yöntemleri üzerinde durulmaktadır. Eğitim kurumlarının müfredat hazırlıklarında uyum becerilerinin anlaşılması önemlidir.

\section{Beceri Nedir?}

Beceri; belirli bazı motor fonksiyonların veya araç gerecin belli bir düzeydeki ustalıkla belirli bazı görevleri yerine getirebilmek üzere kullanılmasıdır. ${ }^{11}$

Öğrencilere kazandırıması amaçlanan öğrenmeler içerisinde bilişsel-düşünsel-kavramsal (cognitive, thinking), duyuşsal-duyusal-duygusal (affective, emotion/feeling) ve psikomotor-devimsel-fiziksel (psychomotor, physical/kinesthetic) özellikler içeren kazanımlar yer almaktadır. ${ }^{12,13}$

Psikomotor becerilerin kazanılması bir süreç işidir ve tıpkı bilişsel ve duyuşsal davranışlarda olduğu gibi kendi içinde basitten karmaşığa, somuttan soyuta bir sıra izler. Günümüze kadar birçok eğitim bilimci devimsel alanı sınıflandırmaya çalışmıştır. ${ }^{14}$

\section{Psikomotor becerilerin kazanılmasıyla ilgili temel aşamalar ${ }^{15}$}

- Uyarıma: Beceriyle ilgili alanın model ya da örneklerin belirli süre ve yeterlikte öğrenciye sunulması, nasıl yapıldığını izletme (öğrencinin hareket için bilişsel, duyuşsal, devimsel yönden hazır duruma gelmesini sağlamabedensel kuruluş). 
- Kılavuz denetiminde yapabilme: Beceriyi oluşturan basamakların tümünün eğitmen gözetiminde öğrenci tarafından yapılmasını sağlama.

- Beceri haline getirebilme: Beceriyi kendi başına, kimseden yardım almadan, gereken nitelikte ve belirtilen sürede yapma.

- Duruma uydurabilme: Önceden kazanılan beceriyi yeni durumlarda, kimseden yardım almadan kullanma.

- Yaratabilme: Yeni, özgün bir beceri geliştirebilme.

\section{Beceride kaydedilen aşamalar ${ }^{15}$}

- Beceri kazanma: Klinik beceriyi öğrenmedeki ilk dönemdir. Bir beceriyi uygulamak için bilinmesi gereken aşamaların sırasının birkaç uygulamadan sonra öğrenilmesidir. Doğru biçimde yapılmasını sağlamak için öğrencilere yardım etmek gerekir. Kontrol listeleri ve öğrenim rehberleri büyük önem taşır.

- Beceride yeterlik: Ara dönemi tanımlar. Öğrenci basamakları doğru sırada uygulayabilir; ancak bazı basamaklarda takılabilir.

- Beceride ustalık: Beceriyi öğrenmede son dönemdir. Öğrenci basamakları ve gerekiyorsa basamakların sırasını bilir; tam ve yetkin bir biçimde uygular.

Öğrencilerin öğrenme stratejilerini yerine getirme ve bilgilerini arttırmak için eğitilmelerinin, motivasyon ve performansları üzerinde olumlu etkiye sahip olduğu bilinmektedir. ${ }^{16-18}$ Tıp eğitiminin her aşamasında, öğrenme stratejileriyle ilgili eğitim aktivitelerinin planlanmasının da bu nedenle öğrencilerin eğitiminde fayda sağlayacağı bildirilmiştir. ${ }^{19}$ Diş hekimliği; müfredatın bilimsel yapısı nedeniyle daha çok teknik beceriler üzerinde yoğunlaşır. Mesleki beceriler ve uyum becerileri (soft skills) kazandııımasını içeren 21. yüzyıl müfredat innovasyon çalışmalarına öğretme ve öğrenme aktivitelerinin de entegre edilmesi öğrencilerin öğrenim çıktıları ve performanslarını kuşkusuz etkileyecektir. ${ }^{20}$

\section{Diş Hekimliği Lisans Eğitimi için Mesleki Becerilerin Kapsamı}

Diş Hekimliği Fakültesinden mezun olan bir hekimin, belirli düzeylerde yapması ve yönetmesi gereken temel diş hekimliği uygulamalarını içerir. Temel diş hekimliği uygulamaları Diş Hekimliği Ulusal Çekirdek Eğitim Programında (DUÇEP) aşağıdaki başlıklar altında toplanmıştır: ${ }^{21}$

1. Öykü alma

2. Genel ve soruna yönelik ağız dışı ve ağız içi muayene

3. Kayit tutma, raporlama ve bildirim

4. Laboratuvar testleri ve ilgili diğer işlemler

5. Girişimsel ve girişimsel olmayan uygulamalar

6. Koruyucu diş hekimliği, toplum ağız ve diş sağlığı uygulamaları

7. Çevresel (fiziksel ve sosyokültürel çevre)/ küresel durum uygulamaları

8. Adli ve/veya psikososyal durum uygulamaları

\section{Diş Hekimliği Uygulamaları Öğrenme Düzeyleri}

Diş hekimliği fakültesinden mezun olan hekimin, temel hekimlik uygulamaları sırasında sergilemesi gereken performansın, dolayısıyla öğrenmenin asgari düzeyini belirtir. Asgari düzey, DUÇEP’teki mesleki uygulamalar 
listesinde her bir beceri/uygulama için ayrı ayrı belirlenmiştir. Bunlar aynı zamanda her bir hastalık ve klinik problemin öğrenme düzeyini gösterir ve diş hekimliği fakülteleri uyguladıkları eğitim süresi içinde, söz konusu hastalık veya klinik problem için belirlenen asgari düzeydeki kazanımı her bir öğrenci için sağlamalıdır. ${ }^{21}$

Öğrenme düzeyleri aşağıdaki şekilde tanımlanmaktadır:

A: Acil durumu tanımlayarak acil tedavisini yapabilmeli, gerektiğinde uzmana yönlendirebilmeli

ÖnT: Ön tanı koyarak, kesin tanı için uzmana yönlendirebilmeli

T: Tanı koyabilmeli ve tedavi hakkında bilgi sahibi olmalı, gerekli ön işlemleri yaparak, uzmana yönlendirebilmeli

TT: Tanı koyabilmeli, tedavi edebilmeli

K: Korunma önlemlerini (primordial, birincil, ikincil ve üçüncül korunmadan uygun olan/olanları) uygulayabilmeli

R: Rehabilitasyon

Öğrenme çıktıları ve mezuniyet yeterliklerine göre her bir anabilim dalında yaparak uygulaması sağlanacak klinik beceri listesi belirlenir. Klinik uygulama (beceri) çeşitlerinin öğrencilerin klinik eğitim seviyelerine göre belirlenmesi de ayrıca önem taşır. Klinik uygulamaya yeni başlayan veya tamamlama seviyesinde olan öğrencilerden benzer sorumluluk veya beceri göstermeleri beklenemez.

\section{Yüzyıl Becerileri Nelerdir?}

Mezun diş hekimlerinin sadece klinik yeterlik kazanmakla kalmayıp, topluma hizmet sunabilmek için iyi uyum (21. yüzyıl) becerilerine sahip olmaları da gerekir. Klinik, bilimsel ve çevreyle uyum becerileri dental müfredatın önemli bileşenleri olarak tanımlanır; zira bu şekilde öğrenciler hastalarını empati anlayışı ile dinleyip, sorgulayabilir ve sonuçta hastaların da kendi ağız sağlığı durumları ve intiyaçlarını anlamalarına yardımcı olurlar. ${ }^{22}$

İletişim, ilişkiler ve işbirliği becerileri; öğrencilerin motive olması için önemlidir; ki bunlar öğrencileri gelecekte eleştirel düşünerek ve amaçları doğrultusunda harekete geçmeleri için cesaretlendirecektir. ${ }^{23}$

Uyum becerileri; (1) iletişim, (2) eleştirel düşünme ve problem çözme, (3) takım çalışması gücü, (4) hayat boyu öğrenme ve bilgi yönetimi, (5) girişimcilik, (6) etik, ahlak ve profesyonellik ve (7) liderlik becerileri olarak tanımlanmıştır. ${ }^{22-24}$

Klinik yeterlik; sosyal, kültürel ve politik ortamlara hassasiyeti gerektiren klinik uygulamalarda iletişim becerileri, kritik düşünme, profesyonellik ve bilgi yönetimini kullanarak problemlerin tanımlanması ve çözümüyle gerçekleşir. ${ }^{25}$ Uyum becerilerinin öğretilmesinde konferanslar, seminerler, vakaya dayalı çalışmalar, probleme dayalı eğitim, proje görevleri, klinik simülasyon laboratuvar aktiviteleri gibi farklı eğitim yöntemleri kullanılmıştır. ${ }^{26-28}$ Uyum becerilerinin öğretilmesi ve değerlendirilmesi için yöntemler halen tartışmalıdır. 


\section{Yüzyıl becerilerinin bileşen ve alt bileşenleri}

Uyum becerisi öğeleri üzerine bir rehber oluşturulmuş ve bunların nasıl öğretileceği ve değerlendirileceği üniversitelere bırakılmıştır. ${ }^{24}$ Lisans eğitiminde hangi uyum becerisi öğesinin geliştirilmesi gerektiğini üniversitelerin tanımlaması ve müfredatlarında yer vermeleri gerekir. ${ }^{29-31}$ Uyum becerilerinin bileşen ve alt bileşenleri şunlardır:

- Iletişim becerileri

○ Fikirleri açıkça, etkili ve kendine güvenerek sözlü ve yazılı olarak sunabilme

- Aktif dinleme becerilerini yapabilme ve geri bildirim üretebilme

○ Dinleyicinin düzeyine uygun olarak açık ve kendine güvenerek sunabilme

- Sunumlarda teknolojiyi kullanabilme

- Tartışma yapabilme ve uzlaşma sağlayabilme

○ Farklı kültürlerden kişilerle iletişime geçebilme

- Kişilerarası iletişim becerilerini geliştirebilme

○ Sözsüz becerileri kullanabilme

- Eleştirel düşünme ve problem çözme becerileri

- Kompleks ve belirsiz durumlarda problemleri tanımlayıp analiz edebilme ve savunulabilir değerlendirmeler yapabilme

○ Düşünme becerilerini geliştirebilme ve ilerletebilme; tartışmaları açıklama, analiz etme ve değerlendirebilme

○ Fikirler ve alternatif çözümler bulabilme

○ Düşünceyi kalıp dışına çıkarabilme

○ Somut kanitlar üzerinde kararlar oluşturabilme

○ Verilen görev üzerine tamamen konsantre olabilme ve koruyabilme

○ Toplumun ve yeni çalışma ortamının kültürünü anlayabilme ve uyum sağlayabilme

- Takım çalışma becerileri

- Aynı amaçları elde etmek üzere diğerleriyle iyi ilişki kurabilme, etkileşebilme ve etkili çalışabilme

○ Takım lideri ve takım üyelerini anlayabilme ve rolleri değişebilme

- Diğerlerinin tavır, davranış ve inançlarını tanıyabilme ve saygı duyabilme

- Takımın çabalarının düzenlenmesi ve planlamasına katkıda bulunabilme

- Grubun kararlarının sorumluluğunu alabilme

- Yaşam boyu öğrenme becerileri

- Farklı kaynaklardan konuyla ilgili bilgiyi tarayabilme ve yönetebilme 
- Yeni fikirleri kabul edebilme ve bağımsız öğrenmeyi yapabilme

- Meraklı bir zihin geliştirebilme ve bilgiye aç olabilme

- Girişim becerileri

○ İş fırsatlarını tanımlayabilme

- İş taslaklarını oluşturabilme

- İş ve çalışmayı inşa edebilme, keşfedebilme ve ele geçirebilme

- Bağımsız olarak çalışabilme

- Profesyonel etik ve ahlak becerileri

- Profesyonel hayatta ekonomi, çevre ve sosyo-kültürel etkileri tanıyabilme

○ Etikle ilgili problemlerin çözümü için analiz ve kararlar oluşturabilme

- Topluma karşı sorumlu hissetme dışında da etik çalışabilme

- Liderlik becerileri

- Temel liderlik teorisi bilgisine sahip olma

- Projeye liderlik edebilme

○ Takım lideri ve takım üyelerini anlayabilme ve rolleri değişebilme

○ Takım üyelerini yönetebilme

İletişim becerilerinin eğitiminde çoğunlukla didaktik (teorik) eğitimle birlikte simülasyon (standardize) hastalar üzerinde klinik rol yapma yöntemi kullanılmaktadır. ${ }^{26}$ Etkili iletişimin tedavi edici özellikte olduğu, hastanın fiziksel ve emosyonel olarak iyi hissetmesine ve kavramasına katkı sağladığı bilinmektedir; diğer elemanları ise güven, empati, saygı ve kişisel farkındalıktır. ${ }^{31-33}$

İletişimin etkili olabilmesi için hasta ve hekim arasında güvenden önce karşılıklı saygı oluşmalıdır. Hastaların olumsuz dental geçmişleriyle ilişkili olarak görülen dental korkular ve anksiyeteyi azaltmak için diş hekimlerinin ileri iletişim becerilerine sahip olması gerekir. ${ }^{33}$ Terapötik iletişimin faydaları; hastanın anksiyetesinde azalmayla birlikte hasta memnuniyetinde artıştır. ${ }^{32}$

Hekimlerin etkili iletişim becerisine sahip olması durumunda, hasta memnuniyetinin, hastanın tavsiyelere olan uyumunun ve tedaviden sağlanan faydanın arttığı; hasta anksiyetesi ve hatalı hekim uygulamasından kaynaklanan şikayetlerin azaldığı bildirilmiştir. ${ }^{27,34,35} \mathrm{Bu}$ nedenle diş hekimliği öğrencilerinin iletişim becerilerinin arttıııması için daha fazla dikkat edilmesi ve dental müfredatta mutlaka yer verilmesi gerekir. Diş hekimliği öğrencileri de geri bildirimlerinde, iletişim becerilerinin diğer klinik beceriler kadar önemli olduğunu ve uygulamalı eğitimde yer alması gerektiğini ifade etmişlerdir. ${ }^{36}$

İletişim becerilerinin eğitim yöntemleri arasında sunumlar, simülasyon hastalar üzerinde rol yapma uygulamaları, gerçek hastalarla görüşmeler, geri bildirim, internet aracılığılla eğitim ve kompleks vakalarda uygulamalar yer almaktadır. $^{37}$ 
Standardize hastalar; kendilerini kendi durumlarını ortaya koyabilen uzmanlar olarak düşündüklerinden, tıp öğrencilerinin yetiştirilmesinde emeği geçen önemli kişiler olarak görürler. ${ }^{38}$ Eğitimciler ve öğrenciler de hastaların tıp eğitiminde eğitmen olmaları konusunda ciddi destek vermektedir. ${ }^{39}$ Hasta eğitimciler eğitim ortamını; gerçeklik katarak kolaylaştıır ve aptalca sorulan sorulara izin vererek hatalardan öğrenme yolunu açar. ${ }^{40}$ Hasta eğitmenler ve öğrenciler arasında dengeli bir güç oluşturmak öğrenmeyi mantıklı ve geçerli kılar. Öğrencilerin hastalarla olan iletişimlerini incelemek için farklı öğretme ve değerlendirme yöntemleri mevcuttur; bu amaçla hastalardan geri bildirim alınması yönteminin hastalar ve öğrenciler tarafından nasıl algılandığı incelenmiş; hem hastalar hem de öğrencilerin bu konuda çok istekli olduğu ve her iki taraf açısından faydalı olduğu bildirilimiştir. ${ }^{38}$

Dental iletişim becerisi eğitiminin geliştirilmesini kolaylaştırmak için görüşler, örnek bir müfredat oluşumu ve bu tarz eğitimin benimsenmesi için engeller ve kolaylıkların listesi hazırlanmıştır. ${ }^{41}$ iletiş̧im becerilerinin eğitimi için bir müfredat örneği Tablo 1'de sunulmuştur.

İletişimle ilgili görüşler 4 ayrı grupta rapor edilmiştir. Mezun ettikleri öğrencilerinin iletişim becerilerini iyileştirmek isteyen fakülteler; bu veriler ışığında bir müfredat hazırlayabilirler.

1. Iletişim becerisi eğitiminin yararı, öğrenci memnuniyeti ve öneminin algısı: Illetişim becerisi tüm öğrenciler tarafından keyifli ve faydalı bulunmuş; öğrencilerin iletişim becerilerini iyileştirdiği üzerinde durularak, diş hekimliği eğitiminde iletişim becerisi eğitiminin yer almasının önemine dikkat çekilmiştir. ${ }^{42,43}$

2. Iletişim becerisi eğitiminde eğitmenin rolü: Davranış modeli ve deneyimlerin paylaşılması açısından eğitmenin etkileri tartışılmışır. Eğitmen davranışlarının rol model oluşturarak, öğrencilerin uygulamalarını desteklediği belirtilmiştir. İstenen davranışların şekillendirilmesi ve geri bildirim; öğrencilerin kendi davranışlarını şekillendirmesine yardımcı olan esaslardır. ${ }^{43,44}$

3. Iletişim becerisi eğitiminde çeşitliliği sağlamanın önemi: Öğrenciler hem akranları hem de hastalarla olan iletişimlerinde kültür ve cinsiyet çeşitliliğinin farkındalığını oluşturmada zorluk çekebilirler. ${ }^{28,42,45,46}$ Öğrenciler; sadece değişik demografik grup ve geçmişe sahip hastalarla iletişim kuramama sıkıntısıyla kalmayıp, öğrenci popülasyonundaki kültürel, sosyoekonomik ve cinsiyete bağlı farklılıklar nedeniyle de iletişim becerisi eğitimindeki performans ve tavırlarında sıkıntı yaşamışlardır. ${ }^{45,46} \mathrm{~K} ı \mathrm{z}$ öğrenciler; iletişim becerisi eğitimini erkeklere göre daha olumlu karşılamış ${ }^{44}$ ve değerlendirmelerde erkek akranlarına göre daha üstün performans göstermişlerdir. ${ }^{47}$

4. Iletişim becerisi eğitiminde planlamaya yönelik düşünceler: Fazla klinik tecrübesi olan öğrenciler; muhtemelen daha fazla hastayla temas halinde olduklarından, iletişim becerisi eğitiminin daha önemsiz veya onlara daha az faydalı olduğunu ifade etmişlerdir. ${ }^{42,48}$ Ders içeriklerinin zamanlamasına dikkat çekilmiş; ayrıca teorik derslere ilaveten deneysel öğrenme uygulamalarının da iletişim becerisi eğitimine katılması gerektiği bildirilmiştir. ${ }^{48}$

Eleştirel düşünme becerisinin eğitimi de çoğunlukla teorik yöntemle yapılmakta ve 4 yöntem önerilmektedir: ${ }^{49}$

1. Problem analizi gerektiren durumda eğitmenin sorgulanması, farklı yaklaşımların karşılaşı̧ıılması, dersin sonuçlarının verilmesi

2. İşlemin tartışılmasında, problemin analizi ve problem çözümü için uzmanların dinlenmesi

3. Mevcut senaryo üzerinde uzmanlar tarafından kullanılan stratejilerin karşılaştırıması 
4. Problem analizinde; sebep olan faktörler, alternatif çözümlerin mukayesesi ve gerekçelendirmeyi içeren raporların düzenlenmesi

Tablo 1. İletişim becerileri eğitimi için müfredat örneği. ${ }^{41}$

\begin{tabular}{|c|c|c|}
\hline Eğitim Yöntemi & Eğitim Dönemi & Konu Başlıkları \\
\hline \multirow{4}{*}{ Teorik } & İlk Sene & $\begin{array}{ll}\text { - } & \text { Genel iletişime giriş } \\
\text { - } & \text { Diş hekimliği fakültesinin kültürü, stres } \\
& \text { yönetimi, tükenmişlikten korunma/esneklik } \\
\text { - } & \text { Eleştirme ve eleştirilme şekilleri } \\
\text { - } & \text { Fakülte üyeleri ve akranlarla zor görüşmeler } \\
\text { - } \quad \text { Kendi kendini değerlendirme }\end{array}$ \\
\hline & İkinci Sene & $\begin{array}{l}\text { - Hasta ile iletişime giriş (telefon görüşmeleri, kısa } \\
\text { görüşmeler, göz teması vs) } \\
\text { - } \quad \text { Empatik dinleme, çözüm odaklı } \\
\text { terapi/motivasyonel görüşmeler } \\
\text { - } \quad \text { Kültürel zitlıklara giriş }\end{array}$ \\
\hline & Üçüncü Sene & $\begin{array}{l}\text { - Hasta ile zor görüşmeler/ağlayan hastalarla } \\
\text { başetme } \\
\text { - Dental anksiyete }\end{array}$ \\
\hline & Dördüncü Sene & $\begin{array}{l}\text { - Dental personelle, diğer hekimlerle, uzmanlarla, } \\
\text { laboratuvarla ve doktorlarla iletişim } \\
\text { - Diş hekimliği ve kültür ilişkisi } \\
\text { - Yatıştırma durumları }\end{array}$ \\
\hline \multirow{4}{*}{ Uygulama } & \begin{tabular}{|l} 
İlk Sene \\
\end{tabular} & $\begin{array}{l}\text { - Stres yönetimi grup çalışması } \\
\text { - Sinıf arkadaşlarıyla zor görüşmeleri rol yapma } \\
\text { yöntemiyle kaydetme } \\
\text { - Kendi kendini değerlendirme dergileri, videoları } \\
\text { ve ropörtajları }\end{array}$ \\
\hline & İkinci Sene & $\begin{array}{l}\text { - Standardize hastalarla telefon görüşmeleri ve } \\
\text { tedavi öncesi görüşmeler } \\
\text { - Zitlıklar üzerine panel tartışmaları }\end{array}$ \\
\hline & Üçüncü Sene & $\begin{array}{l}\text { - Hastalar ve diş hekimleriyle panel tartışmaları } \\
\text { - Zor görüşmeleri rol yapma yöntemiyle kaydetme } \\
\text { - Standardize hastalarla hastaların stres yönetimi }\end{array}$ \\
\hline & Dördüncü Sene & $\begin{array}{l}\text { - Yatıştırıcı durumları rol yapma yöntemiyle } \\
\text { - } \\
\text { - Paydetme } \\
\text { ve mestekisyen diş hekimligütten hekimlerle panel tartışmaları }\end{array}$ \\
\hline
\end{tabular}

Johnsen ve ark. ${ }^{50}$ eleştirel düşünme eğitimini 3 aşamada tarif etmiştir. İlk aşamada; probleme dayalı eğitimin ardından preklinik sınıflarında eleştirel düşünmenin konseptine giriş, literatür araştırması ve kanıta dayalı diş 
hekimliği anlatımaktadır. Sonraki aşamada; klinik eğitime geçilir ve farklı anabilim dalları küçük grup öğrencilerle hasta değerlendirmesi, tedavi planlaması konularında öğrencilere rehberlik ederler. Son aşamada anabilim dalları; tedavi planlamalarını ve analitik işlemleri içeren diğer aktiviteleri desteklemek için klinik raporları gözden geçirir. Probleme dayalı ve vaka örnekleri olan seminerlerin eleştirel düşünmenin gelişimi için verimli ortam oluşturduğu bildirilmektedir. ${ }^{51}$ Eğitmenlerin kendi eğitimlerinde de eleştirel düşünme yöntemini kullanmış olmalarının faydasından söz edilir; zira öğrenciler eğitmenlerini rol model olarak kabul ederler ve eğitmenler öğrencilerini bu yönde özendirmelidir. ${ }^{52}$

Mezunların eleştirel düşünme becerilerinde yetersizlik olduğuna dikkat çekilmiş;;3-55 öğrencilerin hastalarına tedavi seçeneklerini anlatırken problem yaşadığı bildirilmiştir. ${ }^{56} \mathrm{Bu}$ durumun deneyim eksiklikleri veya dental kliniklerde öğrendiklerini entegre edememeleri nedeniyle ortaya çıktığı düşünülmektedir. Diş hekimliği fakültelerinde her biri ayrı değerlendirme kriterleri ve koşulları olan farklı anabilim dalları kliniklerinin mevcut olması, öğrencilerin tedavi planlama becerilerini sınırlandırmaktadır. ${ }^{22}$

Eleştirel düşünme performansının araşırma planlama, istatistik yöntemler ve prensiplerinin bilinmesiyle artmadığı; eleştirel olmakla ilgili olduğu; eleştirel düşünme ve klinik performans için kişisel faktörlerin belirleyici olabileceği ifade edilmektedir. ${ }^{56}$

Eleştirel düşünmeyi geliştirmek için gereken eğitim stratejilerinin, yeterlik ve akıl yürütmenin ölçülmesi için gereken ölçme ve değerlendirme ölçütlerindeki eksikliklerle engellendiği ileri sürülür. ${ }^{50}$ Eleştirel düşünme; değerlendirme yöntemlerinde en çok ele alınan kriter olmasına rağmen, yöntemlerin uygun olup olmadığı araştırılmamıştır. ${ }^{57}$

Mevcut öğretme yöntemleri öğrencilerin spesifik klinik vakalardaki eleştirel düşünme yeteneklerini değerlendirmek için yeterince objektif ve sistematik olmadığından, uzman görüşünü sistematik olarak uygulayan yeni bir değerlendirme yöntemi önerilmiştir. ${ }^{58} \mathrm{Bu}$ sistemde öğrenciler son karara varmadan önce alternatifleri gözden geçirdiklerinden, karar verme, sentezleme ve yaratıclık özelliklerini kullanarak; tedavi planlaması, literatür taraması ve incelemesi, risk değerlendirmesi, kanıta-dayalı diş hekimliği ve davranış yönlendirmesi yaparlar. Bu değerlendirme yönteminin 2 avantajı vardır: İlki ve belki de en önemlisi; uzman görüşü istenen sonuç, öğrenme rehberi ve değerlendirme dökümanıdır. İkincisi; bu yöntemde uzman görüşü sistematik olarak uygulanır. Deneyimli klinisyenlerin tedavi planlamaları yaparken sıklıkla farklı sonuçlara ulaşabildiklerini dikkate alan bir sistemdir.

Sistem şu şekilde planlanır: (1) Belirlenen bir durum üzerinde fakültedeki uzmanların görüşünü almak için görüşmeler yapılır. Amaç; öğrencilerin kolayca uygulayabilecekleri bir uzman görüşü sistemini açık bir şekilde dile getirmektir. (2) Eleştirel düşünmeyle ilişkili beceriler değerlendirilir; içeriği ve uygulanmasında fakültedeki uzmanlar arasında bir uzlaşma oluşturulur. Uzmanlar arasında fikir birliğine ulaşmak çok önemlidir; çünkü öğrenimi yönlendirmek ve performansı değerlendirmek için bu sistem aynı dökumanı kullanır. (3) Sistem içinde alternatifler, ön yargılar ve kendi kendine değerlendirme de yer alır. Öğrencinin bir durum hakkında son kararı verme veya girişimde bulunmadan önce, savunulabilir alternatiflere yönlenmesi sağlanır.

Takım içinde çalışma yeteneği; diş hekimliği pratiğinde önemli yer tutar ve dental literatür diş hekimliği öğrencilerine takım çalışmasını öğretmek için disiplinlerarası eğitim üzerinde yoğunlaşmaktadır. ${ }^{59}$ Leisnert ve ark. $^{60}$ diş hekimliği ve yardımcı personel eğitimi alan öğrencileri bir arada çalıştırarak, takım çalışması becerilerini geliştirmeleri, hastaların durumu üzerinde daha iyi bakış açısı edinmeleri ve birbirlerinin mesleklerini daha iyi algılamaları için İsveç’te bir proje başlatmıştı. Her iki öğrenci grubunda da, hastalarının tedavi planlamasını ve 
tedavilerini yaparken oluşturulan aktiviteler faydalı bulunmuştur. Takım çalışmalarını geliştirmek için probleme dayalı eğitim yöntemi de kullanılmaktadır; öğrencilerin kendilerine takım olarak sunulan problemi analiz etmesi ve görüşlerini desteklemek için kanıtları kullanmaları beklenir. Öğrenciler problemleri çözerken, rollerini paylaşır ve partnerleriyle iletişime geçerler. ${ }^{22}$

Liderlik; dental eğitim programlarında en iyi geliştirilen beceridir. ${ }^{61}$ Öğrenciler liderlik programlarında rol model olarak görev almak için istekli olmalarına rağmen, müfredatta bu programlar sınırlıdır. ${ }^{61,62}$ Liderlik teorisi ve becerileri preklinik ve klinik uygulamaların yönetilmesinde, Harvard Üniversitesi'ndeki üçüncü sınıf öğrencilerinde olumlu sonuçlar vermiştir. ${ }^{63}$

Profesyonel etik ve ahlak eğitimi; diş hekimlerini sosyal ve profesyonel olarak insanlıktan sorumlu yetişkinler yapar. Bu değerlerin öğretilmesi için en uygun yöntemin konferans ve seminerler olduğu bildirilmiştir. ${ }^{59}$ Etik uygulamalar probleme dayalı eğitim dersleri ve vaka sunumlarında yer alabilir.

Brondani ve Rosoff ${ }^{64}$ standardize hastalarda "rol yapma" ve "küçük grup sunumları" ile oluşturduğu stratejide, öğrencilerin etik olmasına çalışmak yerine, onların etik ikilemi anlamalarına ve doğru kararlar almalarına çalışmıştır. Diş hekimleri neredeyse her gün etik ve profesyonel meselelerle karşılaşır; klinik kararlar ve etik meseleleri yönetme konusunda sorun yaşarlar. ${ }^{65}$ lowa Üniversitesi dördüncü sınıf öğrencilerinde, etik meseleler sınırlı kaynakları olan ve hastaların yerine geçen bireylerle birlikte, klinik davranış biçimi veya işlemler ve kararlar şeklinde, okul dışı programlarda uygulanmıştır. ${ }^{29}$ Etiğin diş hekimliği fakültelerinde öğretilmesini incelemek için bir araştırma ${ }^{65}$ yapılmış; karşılanmamış intiyaçlar, etiğin müfredat içindeki entegrasyonu, etik yeterliğin değerlendirilmesi ve sağlanması ile fakültenin eğitim yöntemi konusuna dikkat çekmesi ve gelişimi gibi konular üzerinde durulmuştur.

Yaşam boyu öğrenme okullarda zorunlu tutulabilir ve bu konuda farklı öğretim stratejileri mevcuttur. Bu yöntemlerden biri öz-değerlendirmedir. Redwood ve ark. ${ }^{66}$ birinci sınıf öğrencilerine klinik değerlendirme için kullanılan kriterler ve standartların öğretimindeki gelişmeyi belirlemek için bir çalıştay hazırlamış; bu programın öğrencilerin yaşam boyu öğrenme için ihtiyaç duydukları becerileri geliştirmelerine faydalı olacağını ileri sürmüştür. Toronto Üniversitesi'nde 1992'de ders anlatmaya dayanan (lecture-based) müfredat değiştirilmiş; küçük gruplar, probleme dayalı eğitim ve kendi kendine yönlendirilen öğrenme (self-directed learning) fırsatlarının yer aldığı çok yönlü (hybrid) müfredat uygulanmıştır. ${ }^{67}$ Yaşam boyu öğrenme uygulaması; öğrencilere ne öğrendiklerinin ilgisini kurma ve mesleki sorumluluklarını anlamaları için memnuniyet oluşturan verimli bir ortam sağlar. ${ }^{68}$ Bu gözlem; probleme dayalı eğitim veren okullarda öğrenim modeli olarak da kullanılabilir. Malezya Sains Üniversitesi öğrencileri; probleme dayalı eğitim oturumlarının, öğrenim amaçlarını kavramaları ve çalışma konularını derinlemesine anlamaları, temel bilimsel konuların klinik becerilerle bağlantısını kurmaları ve grup etkileşim becerilerini geliştirmelerine faydalı olduğu görüşüne varmışlardır. ${ }^{69}$

Diş hekimlerinin her gün güncel bilgideki gelişmeyi takip etmeleri için mesleki sorumlulukları olarak yaşam boyu öğrenmeye kendilerini adamaları gerekir. ${ }^{67}$ Mezuniyet sonrası programlarla mukayese edildiğinde, lisans programlarında yaşam boyu öğrenmeyle ilgili çok az içerik mevcuttur.

İletişim becerisi; eleştirel düşünme, problem çözme, takım çalışması, liderlik ile profesyonel etik ve ahlak gibi diğer uyum becerilerinin gelişimi ile ilişkilidir; ancak hem öğretim hem de değerlendirme yönünden fakültelerde eşit derecede ele alınmamaktadır. ${ }^{28}$ Oysa ki; hasta merkezli (patient-centered) fakültelerde, öğrencilerin iletişim 
becerilerinin geliştirilmesi önemlidir. ${ }^{70}$ Birçok çalışmada "öğrenci iletişim değerlendirme ölçeği" ve "hasta iletişim değerlendirme ölçeği” gibi 2 araç geliştirilmiştir. ${ }^{70,71}$ Öğrencilerin değerlendirilmesi genellikle hastaların bakış açısı yerine eğitmenler tarafından yapılır. Bir çalışmada ise öğrencilerin iletişim becerilerini değerlendiren ölçek; hastalar ve yardımcı personel tarafından formüle edilmiştir. ${ }^{71}$ Çalışmada; saygılı ve ilgili davranma, bilgiyi paylaşma, takım üyeleriyle iletişim, konforu dikkate alma, profesyonel ilişki kurma ile randevu düzenleme ve takip şeklinde 7 bileşen incelenmiştir. Hasta memnuniyetini etkileyen sosyodemografik faktörleri belirlemek için de bazı ölçekler kullanılmıştır.

Öğrencilerin iletişim becerilerini değerlendirmede "objektif yapılandırılan klinik sınav" (OSCE-objective structured clinical examination) da kullanılmıştır. Öğrencilerin iletişim becerilerinin geliştirilmesinde tek bir eğitimin yeterli olmadığı, kapsamlı programların kullanılması gerektiği vurgulanmıştır. ${ }^{72}$ Diş hekimliği öğrencilerinin uyum becerilerinin ölçülmesinde kullanılacak güvenilir-geçerli bir değerlendirme aracının olmadığı belirtilmiştir. ${ }^{49}$

Malezya'daki diş hekimliği fakültesi mezunlarındaki uyum becerileri eksikliğinin ezberci öğrenim (rote-learning) ve sınava dayalı (examination-based) sistemden kaynaklandığı ileri sürülmüştür. ${ }^{73}$ Benzer eğitim sistemlerini kullanan diğer ülkelerde de durum pek farklı olmayabilir.

Diş hekimliği öğrencilerinin kavramsal-algısal-düşünsel olmayan (noncognitive) becerilerinin başarılarına olan etkileri birçok araştırmaya konu olmuştur. ${ }^{74-78 ~ " K a v r a m s a l ~ o l m a y a n " ~ t e r i m i ; ~ a k a d e m i k ~ d e g ̆ e r l e n d i r m e l e r ~ i l e ~ s ı k l ı k l a ~}$ ölçülen, algı yeteneğinin karşıtı olarak, öğrenci başarısına katkı sağlayabilecek kişisel özellikler, sosyo-duygusal faktörler, tutum ve davranışı tanımlamak için kullanılmaktadır. ${ }^{79-81}$

Öğrencilerin başarıına katkı sağlayan ve eğitmenler tarafından algılanan kavramsal olmayan faktörlerin belirlenmesi ve bu faktörlerin akademik performans, klinik performans ve genel başarıya olan etkilerinin değerlendirilmesi amacıyla yapılan bir araştırmada ${ }^{78} ; 2015-2016$ senelerinde Birleşmiş Milletler'de bir fakültedeki 184 nitelikli eğitmen içinden 43 tanesi çalışmada yer almıştır. Eğitmenler, öğrenci başarısına etki eden kavramsal olmayan faktörleri; iletişim becerileri, öğrenme yaklaşımı, kişisel özellikler, profesyonellik, zıt deneyimler ve teknik yetenekler olarak tanımlamış; akademik performans için hazır bulunuşluk, klinik performans için ise iletişim özeliğinin önemli olduğunu belirtmişlerdir.

\section{SONUÇ}

Mezuniyette gerekli mesleki uygulama becerileri ve yeterlikler; gerek akreditasyon kurumları ve gerekse ulusal programlarda tanımlanmışıı. Eğitim kurumlarının mezunlarına asgari yeterlikleri kazandırmayı hedeflemekle birlikte, 21. yüzyıl becerileri için gereken uygulama ve değerlendirme yöntemlerini geliştirmeleri; sadece "ünlü okul” olma değil, "iyi bir eğitim kurumu” olma başarısına ulaşmaları için fark yaratacaktır. 


\section{KAYNAKLAR}

1. Koole S, Brulle SVD, Christiaens V, Jacquet W, Cosyn J, De Bruyn H. Competence profiles in undergraduate dental education: a comparison between theory and reality. BMC Oral Health 2017; 17:109-17.

2. ADEA. ADEA foundation knowledge and skills for the new general dentist (as approved by the 2011 ADEA house of delegates). J Dent Educ. 2013;77:903-7.

3. Koole S, Vandeweghe S, Mattheos N, De Bruyn H. Implant dentistry education in Europe: 5 years after the Association for Dental Education in Europe consensus report. Eur J Dent Educ. 2014;18:43-51.

4. Clark JD, Robertson LJ, Harden RM. Applying learning outcomes to dental education. $\mathrm{Br}$ Dent $\mathrm{J}$. 2004;196:357-9.

5. Cowpe J, Plasschaert A, Harzer W, Vinkka-Puhakka H, Walmsley AD. Profile and competences for the graduating dentist - update 2009. Eur J Dent Educ. 2010;14:193-202.

6. Gerrow JD, Murphy HJ, Boyd MA. Review and revision of the competencies for a beginning dental practitioner in Canada. J Can Dent Assoc. 2007;73:157-60.

7. Hsu TC, Tsai SSL, Chang JZC, Yu SH, Lai EHH, Lin CP. Core competencies for dental graduates in Taiwan: considering local and cultural issues. J Dent Sci. 2015;11:161-6.

8. Chuenjitwongsa S, Oliver RG, Bullock AD. Competence, competency-based education, and undergraduate dental education: a discussion paper. Eur J Dent Educ 2016; 22:1-8.

9. Chestnutt IG, Gibson J. Clinical dentistry. London, UK: Elsevier Health Sciences, 2007.

10. Sweet J, Wilson J, Pugsley L. Chairside teaching and the perceptions of dental teachers in the UK. Br Dent J 2008: 205:565-569.

11. Burrows RS. Understanding self-assessment in undergraduate dental education. British Dent J 2018; 224:897-900.

12. Albino JE, Young SK, Neumann LM, Kramer GA, Andrieu SC, Henson L. Assessing dental students' competence: best practice recommendations in the performance assessment literature and investigation of current practices in predoctoral dental education. J Dent Educ 2008;72:1405-35.

13. Bertoli E, Lawson KP, Bishop SS. Dental Students' Skills Assessments: Comparisons of Daily Clinical Grades and Clinical and Laboratory Assessments. J Dent Educ 2018; 82:417-23.

14. Linn, R. L. and Gronlund, N. E. Measurement and assesment in teaching.7th edn. New Jersey: Prentice-Hall Inc. 1995.

15. Sönmez V. Program geliştirmede öğretmen el kitabı. Ankara: Anı Yayınclık. 2003.

16. mcKeachie W J, Pintrich P R, Liny G. Teaching learning strategies. Educational Psychologist, 1985; 20:15360.

17. Chalmers D, Fuller R. Research and a Professional development programme on teaching learning strategies as part of course content. International Journal for Academic Development 1999; 4:28-33.

18. Senemoğlu N. Gelişim Öğrenme Öğretim. 12. Baskı, Ankara, Gazi Kitapevi, 2005; sayfa:558.

19. Konakcı S, Velipaşaoğlu S, Musal B. Tıp fakültesi öğrencilerinde öğrenme stratejileri alanında bir çalışma. Tıp Eğitimi Dünyası. 2017;50:31-42.

20. Kereluik K, Mishra P, Fahnoe C, Terry L. What knowledge is of most worth: teacher knowledge for 21st century learning. J Digital Learn Teach Educ 2013;29:127-40. 
21. DUÇEP. Mezuniyet Öncesi Diş Hekimliği Eğitimi Ulusal Çekirdek Eğitimi Programı. Diş Hekimliği Dekanlar Konseyi, 2016.

22. Gonzalez MAG, Abu Kasim NH, Naimie Z. Soft skills and dental education. European J Dent Educ, 2013;17:73-82.

23. Quieng MC, Lim PP, Lucas MRD. 21st Century-based Soft Skills: Spotlight on Non-cognitive Skills in a Cognitive-laden Dentistry Program. European J Contemp Educ 2015;11:71-81.

24. Hottel TL, Hardigan PC. Improvement in interpersonal communication skills of dental students. J Dent Educ 2005;69:281-4.

25. Khatami S, Macentee MI. Evolution of clinical reasoning in dental education. Dent Educ 2011:75:321-8.

26. Carey JA, Madill A, Manogue M. Communication skills in dental education: a systematic review. Eur J Dent Educ 2010;14:69-78.

27. Yoshida T, Milgrom P, Coldwell S. How do US and Canadian dental schools teach interpersonal communication skills? J Dent Educ 2002: 66: 1281-8.

28. Nor NA, Yusof ZY, Shahidan MN. University of Malaya dental students' attitudes towards communication skills learning: implications for dental education. J Dent Educ 2011;75: 1611-9.

29. Sharp HM, Kuthy RA, Heller KE. Ethical dilemmas reported by fourth-year dental students. J Dent Educ 2005:69:1116-22.

30. Scott JE, de Vries J, lacopino AM. 25-year analysis of a dental undergraduate research training program (BSc Dent) at the University of Manitoba Faculty of Dentistry. J Dent Res 2008;87:1085-8.

31. Dunning DG, Lange BM, Madden RD, Tacha KK. Prerequisites in behavioral science and business: opportunities for dental education. J Dent Educ 2011;75:77-81.

32. Sherman JJ, Cramer A. Measurement of changes in empathy during dental school. J Dent Educ 2005;69: $338-45$.

33. Wener ME, Sch€onwetter DJ, Mazurat N. Developing new dental communication skills assessment tools by including patients and other stakeholders. J Dent Educ 2011;75:1527-41.

34. Rouse RA, Hamilton MA. Dentists' technical competence, communication, and personality as predictors of dental patient anxiety. J Behav Med 1990;13:307-19.

35. Huntington B, Kuhn N. Communication gaffes: A root cause of malpractice claims. Proc (Bayl Univ Med Cent) 2003;16:157-61.

36. Prakash T, Philip JM, Abraham HM, Venkatakrishnan JV, Chandran CR. Attitude toward dental communication skills among students in a south indian dental college. Drug İnvent Today 2018;10:1493-5.

37. R€uttermann S, Sobotta A, Hahn P, Kiessling $C$ and $H €$ artl $A$. Teaching and assessment of communication skills in undergraduate dental education - a survey in Germanspeaking countries Eur $\mathrm{J}$ Dent Educ 2017;21:151-8.

38. Coelho $\mathrm{C}$, Pooler J, Lloyd $\mathrm{H}$. Using patients as educators for communication skills: Exploring dental students' and patients' views. Eur J Dent Educ. 2018;22:291-9.

39. Jha V, Quinton ND, Bekker HL, Roberts TE. What educators and students really think about using patients as teachers in medical education: a qualitative study. Med Educ. 2009;43:449-56.

40. Henriksen A-H, Ringsted C. Learning from patients: students' perceptions of patient-instructors. Med Educ. 2011;45:913-9. 
41. Ayn C, Robinson L, Nason A, Lovas J.Determining Recommendations for Improvement of Communication Skills Training in Dental Education: A Scoping Review. J Dent Educ 2017;81:479-88.

42. White JG, Krüger C, Snyman WD. Development and implementation of communication skills in dentistry: an example from South Africa. Eur J Dent Educ 2008;12:29-34.

43. Lanning SK, Ranson SL, Willett RM. Communication skills instruction utilizing interdisciplinary peer teachers: program development and student perceptions. J Dent Educ 2008;72:172-82.

44. Croft $P$, White $D$, Wiskin $C$, Allan $T$. Evaluation by dental students of a communication skills course using professional role-players in a UK school of dentistry. Eur J Dent Educ 2005;9:2-9.

45. McKenzie CT. Dental student attitudes towards communication skills instruction and clinical application. J Dent Educ 2014;78:1388-96.

46. Venturin JS, Durall PS, Enciso R, et al. Comparing methods of cultural competency training and assessment in a predoctoral dental course. J Dent Educ 2013;77:476-84.

47. Memarpour M, Bazrafkan L, Zarei Z. Assessment of dental students' communication skills with patients. J Adv Med Educ Prof 2016;4:33.

48. Lucander H, Knutsson K, Sale H, Jonsson A. "I'll never forget this": evaluating a pilot workshop in ef $\neg$ fective communication for dental students. J Dent Educ 2012;76:1311-6.

49. Hendricson WD, Andrieu SC, Chadwick DG, Chmar JE, Cole JR, George MC. Educational strategies associated with development of problem-solving, critical thinking, and self-directed learning. J Dent Educ 2006;70:925-36.

50. Johnsen DC, Marshall TA, Finkelstein MW, Cunningham-Ford MA, Straub-Morarend CL, Holmes DC. A model for overview of student learning: a matrix of educational outcomes versus methodologies. $J$ Dent Educ 2011;75:160-8.

51. Johnsen DC, Finkelstein MW, Marshall TA, Chalkley YM. A model for critical thinking measurement of dental student performance. J Dent Educ 2009;73:177-83.

52. Behar-Horenstein LS, Schneider-Mitchell G, Graff R. Promoting the teaching of critical thinking skills through faculty development. J Dent Educ 2009;73:665-75.

53. Razak IA, Latifah RR, Jaafar N, Abu HassanMI, Ab Murat N. Assessing the competency of University of Malaya dental graduates: employers' and graduates' perception. J Dent Educ 2008;72:364-9.

54. Yusof ZY, Jaafar N, Jallaludin RL, Abu-Hassan MI, Razak IA. Malaysian dental graduates' competence in holistic care: what do graduates and employers think? J Dent Educ 2010;74: 1380-7.

55. Benbelaid R, Dot D, Levy G, Eid N. Difficulties encountered at the beginning of professional life: results of a 2003 pilot survey among undergraduate students in Paris Rene Descartes University (France). Eur J Dent Educ 2006;10:204-9.

56. Chambers DW. Lessons from students in a critical thinking course: a case for the third pedagogy. J Dent Educ 2009;73:65-85.

57. Montini T, Noble AQA, Stelfox HT. Content analysis of patient complaints. Int $\mathrm{J}$ Qual Health Care 2008;20:412-20. 
58. Marshall TA, Marchini L, Cowen H, Hartshorn JE, Holloway JA, Straub-Morarend JL, Gratton D, Solow CM et al. Critical Thinking Theory to Practice: Using the Expert's Thought Process as Guide for Learning and Assessment. J Dent Educ 2017;81:978-85.

59. Field J, Ellis J, Abbas C, Germain P. Teaching and assessment of professional attitudes in UK dental schools - commentary. Eur J Dent Educ 2010;14:133-5.

60. Leisnert L, Karlsson M, Franklin I, Lindh L, Wretlind K. Improving teamwork between students from two professional programmes in dental education. Eur J Dent Educ 2012;16:17-26.

61. Victoroff KZ, Schneider K, Perry C. Leadership development for dental students: what do students think? J Dent Educ 2008;72:982-8.

62. Victoroff KZ, Schneider K, Perry C. Tomorrow's leaders, starting today: a pilot leadership development program for dental students. J Dent Educ 2009;73:311-8.

63. Kalenderian E, Skoulas A, Timoth e P, Friedland B. Integrating leadership into a practice management curriculum for dental students. Dent Educ 2010;74:464-71.

64. Brondani MA, Rossoff LP. The "hot seat" experience: a multifaceted approach to the teaching of ethics in a dental curriculum. J Dent Educ 2010;74:1220-9.

65. Lantz MS, Bebeau MJ, Zarkowski P. The status of ethics teaching and learning in U.S. dental schools. J Dent Educ 2011;75:1295-309.

66. Redwood C, Winning T, Lekkas D, Townsend G. Improving clinical assessment: evaluating students' ability to identify and apply clinical criteria. Eur J Dent Educ 2010;14:136-44.

67. Polyzois I, Claffey N, Attstr€om R, Kelly A, Mattheos N. The role of the curriculum and other factors in determining the medium- and long-term attitude of the practicing dentist towards life-long learning. Eur $\mathrm{J}$ Dent Educ 2010;14:84-91.

68. Harvey BJ, Rothman Al, Frecker RC. Effect of an undergraduate medical curriculum on students' selfdirected learning. Acad Med 2003;78:1259-65.

69. Barman A, Jaafar R, Naing NN. Perception of students about the problem-based learning sessions conducted for medical and dental schools' students of Universiti Sains Malaysia. Educ Health, 2006;19:3638.

70. Sch€onwetter DJ, Wener ME, Mazurat N. Determining the validity and reliability of clinical communication assessment tools for dental patients and students. J Dent Educ 2012;76:1276-90.

71. Sch€onwetter DJ, Wener ME, Mazurat N, Yakiwchuk B. Exploring the predictive ability of two new complementary instruments for assessing effective therapeutic communication skills of dental and dental hygiene students. J Dent Educ 2012;76:1291-1310.

72. Cannick GF, Horowitz AM, Garr DR, et al. Use of OSCE to evaluate brief communication skills training for dental students. J Dent Educ 2007;71:1203-9.

73. Woo KY. Malaysian private higher education: a need to study the different interpretations of quality. J Adv Sci Arts 2006;1:17-21.

74. Hannah A, Lim BT, Ayers KMS. Emotional intelligence and clinical interview performance of dental students. J Dent Educ 2009;73:1107-17.

75. Schönwetter DJ, Wener ME, Mazurat N. Determining the validity and reliability of clinical communication assessment tools for dental patients and students. J Dent Educ 2012;76:1276-90. 
76. Ihm JJ, Lee G, Kim KK, et al. Who succeeds at dental school? Factors predicting students' academic performance in a dental school in Republic of Korea. J Dent Educ 2013;77:1616-23.

77. Stacey DG, Kurunathan TM. Noncognitive indicators as critical predictors of students' performance in dental school. J Dent Educ 2015;79:1402-10.

78. Virtue SM, Pendergast L, Tellez M, Waldron E, Ismail A. Identifying noncognitive skills that contribute to dental students' success: dental faculty perspectives. J Dent Educ 2017; 81:300-9.

79. Borghans L, Duckworth LE, Heckman JJ, Weel B. The economics and psychology of personal traits. J Human Resourc 2008;43:972-1059.

80. Rosen JA, Glennie EJ, Dalton BW, et al. Noncognitive skills in the classroom: new perspectives on educational research. Research Triangle Park, NC: RTI International, 2010.

81. García E. The need to address noncognitive skills in the education policy agenda. EPI Briefing Paper \#386. Washington, DC: Economic Policy Institute, 2014.

\section{Yazışma Adresi:}

Prof. Dr. Funda AKALTAN

Ankara Üniversitesi Diş Hekimliği Fakültesi

Protetik Diş Tedavisi Anabilim Dalı

Beşevler 06560, Ankara

E-posta : akaltanfunda@gmail.com 